\title{
RACIONALIZACIJA LOGISTIKE NABAVKE NA PRIMERU PROIZVODNE KOMPANIJE
}

\section{RATIONALIZATION OF PROCUREMENT LOGISTICS ON THE MANUFACTURING COMPANY EXAMPLE}

\author{
Srđan Ljiljak, Fakultet tehničkih nauka, Novi Sad
}

\begin{abstract}
Oblast - SAOBRAĆAJ I TRANSPORT
Kratak sadržaj - Težište ovog rada jeste na istraživanju mogućnosti za racionalizaciju procesa snabdevanja potrebnim materijalima. Celokupno istraživanje, a kasnije i primena predloženog rešenja je sprovedeno u kompaniji koja se bavi proizvodnjom cirkulacionih pumpi i pojedinih komponenti koje se ugrađuju u krajnji proizvod. U radu je prvo generalno ukazano na osnovne karakteristike logističkog sistema $i$ funkcije koje realizuje u nekoj kompaniji a nakon toga, opisani su trendovi u logistici sa fokusom na logistiku nabavke. Cilj racionalizacije procesa snabdevanja jeste smanjenje ukupnih troškova nabavke, unapređenje procesa $i$ značajno unapređenje pojedinih performansi poslovanja. Sve analize su urađene na osnovu postojećih lanaca snabdevanja, a rezultati istraživanja su prikazani tabelarno i grafički. Nakon analize, izvršena je identifikacija slabih tačaka lanca snabdevanja, za čije eliminisanje je predloženo rešenje koje bi trebalo da, u relativno kratkom roku, dovede do značajnog unapređenja performansi poslovanja. Na kraju rada, analizirani su efekti primenjenog rešenja kroz poređenje merljivih pokazatelja poslovanja - stanje lanca snabdevanja pre primenjenih mera $i$ nakon primenjenih mera.
\end{abstract}

Ključne reči: Nabavka, racionalizacija, lanac snabdevanja, logistika.

Abstract - The focus of this work is to explore options for rationalization of the supply process. The entire research and later the implementation of the proposed solution was carried out at a manufacturing company. This work first outlines the basic characteristics of the logistics system and the functions that this system realizes in a company. Subsequently, trends in logistics with a focus on procurement logistics are described. The goal of supply process rationalization is to reduce the overall costs of procurement, improve the process and significantly improve individual business performance. All analysis was made on the basis of existing supply chains, and the results of the survey are presented in tables and graphs. Following the analysis, the weaknesses of the supply chain were identified and solution for weak points elimination is suggested. In a relatively short period of time, this solution should lead to a significant improvement in business performance.

\section{NAPOMENA:}

Ovaj rad proistekao je iz master rada čiji mentor je bila prof. dr Svetlana Nikoličić.
At the end of the work, the effects of the applied solution are analyzed through a comparison of measurable indicators of supply chain - state of supply chain before the applied solution and after the applied solution.

Keywords: Purchasing, rationalization, supply chain, logistics.

\section{UVOD}

U današnje vreme, većina kompanija posluje u veoma zahtevnom okruženju sa snažnom konkurencijom. Visoki zahtevi kupaca osim u smislu kvaliteta samog proizvoda koji ne sme da bude upitan, reflektuju se i na polje usluge koju dobijaju od prodavca tj. dobavljača. Kako je kvalitet robe koju može da proizvede više kompanija veoma često dosta ujednačen, razliku među dobavljačima često pravi nivo logističke usluge koju je dobavljač spreman da ponudi kupcu. Kompanije koje nabavljaju određenu vrstu robe, okreću se dobavljačima koji su sposobni da ponude kvalitetniju logističku uslugu pod povoljnijim uslovima.

S tim u vezi, sve kompanije teže da što više unaprede nivo usluge koju mogu da ponude svojim kupcima. Da bi se to ostvarilo, potrebno je da celokupan proces, od nabavke sirovina, preko proizvodnje i na kraju isporuke robe kupcu, bude što efikasniji i usklađeniji. Na ovaj način, smanjuju se troškovi, skraćuju vremena isporuka i na kraju se dobija zadovoljan kupac.

U okviru ovog rada, fokus je na procesima koji značajno utiču na nivo usluge prema krajnjem kupcu - mada se često to ne vidi direktno - a to je logistika nabavke proizvodne kompanije. Tokom izrade ovog rada, obrađen je deo nabavke u proizvodnoj kompaniji koji je prepoznat kao deo koji može znatno biti unapređen i racionalizovan, ukoliko bi se lanac snabdevanja poboljšao.

Prepoznata je slaba karika u jednom delu procesa snabdevanja i osnovni cilj istraživanja bio je da se ponudi rešenje koje bi uz minimalna ulaganja dovelo do rešenja problema i racionalizacije procesa snabdevanja.

\section{LOGISTIKA PROIZVODNIH PREDUZEĆA}

U savremenom društvu, logistika se provlači kroz sve društvene aktivnosti u kojima teži ka optimizaciji korišćenja raspoloživih resursa i usklađivanju procesa $u$ cilju što efikasnije realizacije zadatih ciljeva. Logistika se može definisati kao skup aktivnosti kroz koje se vrši oblikovanje, projektovanje, upravljanje, realizacija i kontrola postupaka na području transporta, manipulisanja i skladištenja robe (1). 
Kada se razmatra logistika preduzeća, potrebno je napomenuti da se ona može definisati na više različitih načina. Međutim, ono što je zajedničko za sve definicije i što se postavlja kao osnovni zahtev pred logistiku u okviru jednog preduzeća je obezbeđivanje potrebnih materijalnih dobara (robe) odgovarajućeg kvaliteta, u optimalnoj količini, u pravo vreme i na pravom mestu, po optimalnim uslovima i ceni koštanja, pravom klijentu ili korisniku.

Funkcija logistike u poslovnim sistemima se razlikuje u zavisnosti od delatnosti i organizacije svakog preduzeća ponaosob, ali najčešće podrazumeva sledeće oblasti:

- logistika nabavke,

- logistika proizvodnje,

- logistika distribucije,

- povratna logistika (2).

Neki od glavnih trendova na području logistike nabavke su:

- geografsko približavanje dobavljača svojim kupcima,

- skraćivanje rokova isporuke robe, visoka frekvencija isporuka i smanjenje minimalnih količina robe koje kupac može da kupi,

- korišćenje konsignacionih skladišta i/ili angažovanje kompanija specijalizovanih za logističke usluge (hotel zaliha),

- praćenje performansi dobavljača kroz sistem KPI1 i PI2,

- upotreba naprednih ERP 3 sistema i njihovo povezivanje (VMI4, EDI5, SNC6),

- ostvarenje ciljeva logistike uz smanjenje uticaja na životnu okolinu.

Rad se detaljno bavi svakim gore navedenim trendom posebno, ali je bitno istaći da se u praksi najčešće koristi kombinacija gore navedenih rešenja u cilju što bolje iskorišćenosti resursa i eliminisanja gubitaka.

\section{OPIS I ANALIZA PROCESA SNABDEVANJA U POSMATRANOJ KOMPANIJI}

Celokupan rad na racionalizaciji procesa snabdevanja urađen je u proizvodnoj kompaniji koja se bavi proizvodnjom cirkulacionih pumpi koje najširu primenu imaju u sistemima centralnog grejanja. Kompanija proizvođač cirkulacionih pumpi (u daljem tekstu ,proizvođač“), u okviru sopstvene proizvodnje poseduje i proizvodnu liniju za proizvodnju statora elektromotora koji se ugrađuju u cirkulacione pumpe. Imajući u vidu činjenicu da proizvođač proizvede oko 2.000.000 cirkulacionih pumpi u toku godine, a samim tim i isti broj statora elektromotora, kao i to da stator elektromotora sa svojom proizvodnom cenom značajno utiče na cenu cirkulacione pumpe, zaključeno je da bi racionalizacijom nabavke materijala koji se koriste za proizvodnju statora elektromotora mogle biti ostvarene značajne uštede.

\footnotetext{
${ }^{1}$ KPI - Key Performance Indicator - Pokazatelj ključnih performansi.

${ }^{2}$ PI - Performance Indicator - Pokazatelj performansi.

${ }^{3}$ ERP - Enterprise resource planning - Planiranje resursa kompanije.

${ }^{4}$ VMI - Vendor-managed inventory - Upravljanje zaliha od strane dobavljača.

${ }^{5}$ EDI - Electronic Data interchange - Elektronska razmena podataka.

${ }^{6} \mathrm{SNC}$ - Supplier Network Collaboration - Sistem/mreža za saradnju sa dobavljačem.
}

Kako bi se utvrdilo koji materijal tj. grupa materijala treba da bude u fokusu procesa racionalizacije, svi materijali potrebni za proizvodnju jednog statora grupisani u četiri grupe prema vrsti materijala (tabela 1), a potom je utvrđeno koliko svaka grupa materijala učestvuje u ceni proizvoda.

Tabela 1 - Učešće različitih grupa materijala u ukupnoj vrednosti materijala koji se koriste za proizvodnju statora

\begin{tabular}{|c|c|c|}
\hline Grupa materijala & Vrednost [RSD] & $\begin{array}{c}\text { Učešće u ceni } \\
\text { proizvoda [\%] }\end{array}$ \\
\hline Bakarna žica & 358,84 & $52 \%$ \\
\hline Laminacioni limovi & 191,71 & $28 \%$ \\
\hline Elemanti električne zaštite & 90,5 & $13 \%$ \\
\hline \hline Ostali materijali & 52,68 & $7 \%$ \\
\hline \hline Ukupno & 693,73 & $100 \%$ \\
\hline
\end{tabular}

Uočljivo je da u poređenju sa ostalim komponentama i materijalima koje proizvođač koristi za proizvodnju statora elektromotora, bakarna žica učestvuje sa više od $50 \%$ ukupne vrednosti nabavke. Sa prosečnom cenom koja iznosi nešto više od $7 \mathrm{EUR} / \mathrm{kg}$, bakarna žica predstavlja pojedinačno najskuplji materijal koji se ugrađuje u stator elektromotora. Imajući u vidu da proizvođač u toku godine utroši oko 700 tona bakarne žice, ukupna vrednost nabavke samo za bakarnu žicu, na godišnjem nivou iznosi oko 5.000.000 EUR.

Iz prethodne analize lako je zaključiti da fokus racionalizacije nabavke treba da bude na nabavci bakarne žice.

Nakon ovoga, analizom lanca snabdevanja bakarne žice, utvrđene su slabosti koje je potrebno ukloniti brzim i relativno jeftinim rešenjem, dok bi ostale slabosti mogle da budu uklonjene u kasnijem periodu. To su:

- udaljenost dobavljača od $1570 \mathrm{~km}$,

- dug rok isporuke od 28 kalendarskih dana,

- visoka vrednost zaliha bakarne žice,

- velike količine bakarne žice na zalihama,

- loš koeficijent obrta zaliha,

- velika zauzetost skladištnog prostora,

- loša povezanost ERP sistema kupca i dobavljača,

- dug proces uvoznog carinjenja robe,

- zarobljena novčana sredstva i negativan uticaj na protok novca (eng. Cash flow).

Pored navedenih, u radu su pomenute i ostale slabosti posmatranog lanca snabdevanja.

\section{PREDLOG MERA ZA UNAPREĐENJE POSTOJEĆEG STANJA}

Nakon identifikacije slabih tačaka i kritičke analize, izvedeni zaključci jasno pokazuju slabosti postojećeg sistema i daju naznake o tome kako bi sistem snabdevanja trebalo da izgleda u budućnosti.

$\mathrm{Na}$ osnovu izvedenih zaključaka o tome koje slabosti budući lanac snabdevanja treba da otkloni, kao jedno od najlogičnijih rešenja nametnula se ideja o prelasku sa postojećeg/tradicionalnog načina snabdevanja na način snabdevanja koji podrazumeva korišćenje tzv. hotela zaliha.

Ukoliko se primeni koncept hotela zaliha na snabdevanje posmatrane kompanije bakarnom žicom, eliminisaće se sledeće slabe tačke: 
- Udaljenost dobavljača - skladište dobavljača bakarne žice iz kog se roba isporučuje se praktično smanjuje sa udaljenosti dobavljač - kupac $(1.570 \mathrm{~km})$ na udaljenost hotel zaliha - kupac $(30 \mathrm{~km})$.

- Dug rok isporuke od 28 dana - smanjenjem udaljenosti između mesta otpreme robe (hotel zaliha) i krajnjeg kupca, logično se znatno smanjuje i potrebno vreme za transport robe.

- Loša povezanost ERP sistema kupca i dobavljača Hotel zaliha podrazumeva povezivanje ERP sistema i direktan uvid dobavljača u planove nabavke kupca robe, što dobavljaču omogućuje bolje planiranje proizvodnje a samim tim i skraćivanje roka potrebnog za proizvodnju robe.

- Dug proces uvoznog carinjenja robe - primenom predloženog rešenja, proces vezan za protok dokumentacije obezbeđuje znatno bržu komunikaciju i pripremu potrebne dokumentacije u napred, tako da je gotovo svako čekanje u procesu uvoznog carinjenja robe izbegnuto.

- Zarobljena novčana sredstva i negativan uticaj na protok novca (eng. Cash flow) - smanjenjem nivoa zaliha, smanjiće se i vezana novčana sredstva, a samim tim, biće ostvaren i pozitivan uticaj na Cash flow.

- Visoka vrednost zaliha bakarne žice i velike količine na zalihama - primenom hotela zaliha, obezbeđeno je da se isporuke robe vrše minimum 2 puta u toku nedelje, što kao posledicu ima smanjenje isporučenih količina, smanjenje količine zaliha i veću fleksibilnost za kupca.

Takođe, novi sistem snabdevanja bi trebao značajno da utiče na unapređenje svih pokazatelja poslovanja koji trenutno pokazuju loše performanse, kao što su koeficijent obrta zaliha robe i veliki broj zauzetih paletnih mesta $u$ skladištu proizvođača.

U radu su detaljno opisani svi potrebni preduslovi za impementaciju hotela zaliha.

\section{EFEKTI POSTIGNUTI SNABDEVANJEM PREKO HOTELA ZALIHA}

$\mathrm{U}$ odnosu na prepoznate slabe tačke i performanse poslovanja koje je trebalo unaprediti, za budući koncept snabdevanja odabran je hotel zaliha.

Nakon 8 meseci primene novog rešenja, urađena je detaljna analiza postignutih efekata. $U$ tabeli 2 , uporedno su prikazane vrednosti određenih pokazatelja poslovanja u posmatranom - početnom slučaju lanca snabdevanja (bez hotela zaliha) i u slučaju kada je primenjeno rešenje lanca snabdevanja sa hotelom zaliha.

Očigledni su efekti na performanse poslovanja, pre svega na: znatno smanjenu vrednost zaliha, značajno smanjene količine zaliha, uticaj na protok novca i „oslobođena“ sredstva koja kompanija sada može da usmeri u investicije ili razvoj.

Nakon sagledanih rezultata tj. efekata primene novog rešenja, posmatrana kompanija je postavila strateški cilj da $\mathrm{u}$ narednom periodu pređe sa klasičnog načina snabdevanja na snabdevanje preko hotela zaliha gde god je to moguće. Fokus bi trebalo da bude na materijalima koji spadaju u grupu High runner-a, zatim materijali koji se nabavljaju od veoma udaljenih kupaca sa dugim rokovima isporuke. Osim navedenih materijala, fokus bi trebalo da bude na materijalima koji imaju visoku jediničnu cenu, visoku cenu transporta, kao i na gabaritnim materijalima koji zauzimaju dosta prostora $\mathrm{u}$ skladištu proizvođača cirkulacionih pumpi.

Tabela 2. Poređenje vrednosti pokazatelja u slučaju lanca snabdevanja bez hotela zaliha i u slučaju lanca snabdevanja sa hotelom zaliha

\begin{tabular}{|c|c|c|c|}
\hline Red. br. & Pokazatelj & \begin{tabular}{|c|} 
Lanac \\
snabdevanje bez \\
hotela zaliha
\end{tabular} & $\begin{array}{l}\text { Lanac snabdevanja } \\
\text { sa hotelom zaliha }\end{array}$ \\
\hline 1 & $\begin{array}{c}\text { Prosečna vrednost zaliha } \\
\text { na kraju meseca [RSD] }\end{array}$ & 93.549 .506 & 36.064 .856 \\
\hline 2 & $\begin{array}{l}\text { Prosečna vrednost zaliha } \\
\text { na kraju meseca [EUR] }\end{array}$ & 757.486 & 292.023 \\
\hline 3 & $\begin{array}{c}\text { Prosečna količina zaliha } \\
\text { na kraju meseca [kg] }\end{array}$ & 109.190 & 46.492 \\
\hline 4 & $\begin{array}{l}\text { Prosečan broj zauzetih } \\
\text { paletnih mesta na kraju } \\
\text { meseca }\end{array}$ & 455 & 196 \\
\hline 5 & $\begin{array}{l}\text { Prosečan koeficijent obrta } \\
\text { zaliha }\end{array}$ & 0,47 & 1,02 \\
\hline 6 & $\begin{array}{l}\text { Udaljenost dobavljač- } \\
\text { kupac }\end{array}$ & $1.570 \mathrm{~km}$ & $30 \mathrm{~km}$ \\
\hline 7 & $\begin{array}{c}\text { Broj isporuka u toku } \\
\text { nedelje }\end{array}$ & 1 & 2 \\
\hline 8 & $\begin{array}{l}\text { Rok isporuke (vreme od } \\
\text { trenutka slanja porudžbine } \\
\text { do isporuke) [broj dana] }\end{array}$ & 28 & 3 \\
\hline 9 & $\begin{array}{l}\text { Vrsta drumskog prevoza } \\
\text { na relaciji Nemačka-Srbija }\end{array}$ & LTL & FTL \\
\hline 10 & Koncept proizvodnje & Make to order & Make to stock \\
\hline
\end{tabular}

\section{ZAKLJUČAK}

Problem koji je kompanija prepoznala u svom poslovanju odnosio se na visoki nivo zaliha povezanih sa određenim proizvodnim procesom. Posledice visokog nivoa zaliha su se ogledale pre svega u ,zarobljenom” kapitalu kompanije, neefikasnoj upotrebi sirovina koja se manifestovala kroz česte pojave tzv. low runner-a, a zatim i na drugim poljima kao što su zauzetost skladišnog prostora, nepotrebne manipulacije teretom, uticaj na zdravlje i bezbednost radnika, itd...

Obzirom na to da je zahtevana relativno brza racionalizacija poslovanja uz minimalna ulaganja, bilo je potrebno da se pronađe rešenje koje bi u okviru postojećih resursa i postojećih zakonskih okvira unapredilo postojeće stanje. Iz tog razloga, nije se išlo u pravcu tehničkih izmena proizvoda ili u pravcu izmene tehnologije procesa proizvodnje, već je prioritet stavljen na unapređenje lanca snabdevanja. Samim tim, fokus ovog rada bio je na racionalizaciji procesa snabdevanja.

Kao rešenje za datu situaciju, predloženo je korišćenje hotela zaliha. Ovim rešenjem, detaljno opisanim u okviru rada, uspešno je eliminisan najveći deo problema kompanije. Najznačajnije, oslobođena su značajna sredstva koja su do primene novog rešenja bila "zarobljena". Prema poređenju egzaktnih podataka o vrednosti zaliha, nakon 12 meseci primene novog rešenja, vrednost zaliha u skladištu proizvođača je smanjena za $70 \%$. Osim toga, masa zaliha nakon 12 meseci je sma- 
njena za $65 \%$, dok je koeficijent obrta zaliha u periodu od 12 meseci više nego udvostručen. Rok isporuke, koji je do primene hotela zaliha iznosio 28 dana, smanjen je na svega 2 do 3 dana. Bitno je naglasiti da je nivo proizvodnje ostao na istom nivou kao i pre implementacije novog rešenja i da se odvija bez ikakvih poremećaja.

Dalja unapređenja procesa u okviru lanca snabdevanja su moguća, pre svega kroz optimizaciju MOQ ${ }^{7}$, tj. upotrebom špulni od $60 \mathrm{~kg}$ umesto špulni od $160 \mathrm{~kg}$. Dodatno, u okviru smanjenja MOQ, treba insistirati na tzv. "picking-u" paleta. "Picking" podrazumeva da se roba može isporučivati na nivou najmanje ambalažne jedinice, a ne samo na nivou palete. Osim ovoga, pojednostavljenje carinskih propisa i procedura bi dovele do daljeg ubrzanja i pojeftinjenja protoka robe.

Iz svega navedenog, može se zaključiti da se primenom inovativnih rešenja u okviru logistike i lanca snabdevanja kao i redizajniranjem postojećih rešenja, može doći do značajnih poboljšanja performansi poslovanja.

Značaj logistike nabavke u okviru kompanija sve više dobija na značaju jer je prepoznato da se kroz racionalizaciju procesa mogu ostvariti značajne uštede i unapređenja performansi. U nekim kompanijama se prilikom razvoja novog proizvoda, od samog početka projektovanja uključuju eksperti iz oblasti logistike, kako bi svojim znanjem već od starta doprineli optimalnom rešenju. Daljom digitalizacijom i unapređenjem planiranja, upotrebom hotela zaliha i sličnih rešenja, uloga logistike nabavke će u budućnosti biti sve više izražena u ostvarenju strateških ciljeva kompanija.

\section{LITERATURA}

[1] Nikoličić, S., Lazić, D: Zelena logistika, Nacionalna konferencija o kvalitetu života 2006., Kragujevac: s.n., 10.-12. maj 2006.

[2] Gajić, V., Nikoličić, S. Skripte sa vežbi i predavanja iz predmeta Logistika preduzeća. Novi Sad : FTN, Departman za saobraćaj, 2003.

\section{Kratka biografija:}

Srđan Ljiljak rođen je u Inđiji 1982. godine. gde je završio osnovnu i srednju školu. Master rad na Fakultetu tehničkih nauka u Novom Sadu na smeru Saobraćaj i transport, sa temom "Racionalizacija logistike nabavke na primeru proizvodne kompanije" odbranio je 2019. godine.

${ }^{7} \mathrm{MOQ}$ - Minimum order quantity - minimalna količina koja se može poručiti. 